Exp Hematol. 2016 May ; 44(5): 390-398. doi:10.1016/j.exphem.2016.01.005.

\title{
Direct evidence of complement activation in HELLP syndrome: a link to atypical hemolytic uremic syndrome
}

\author{
Arthur J. Vaught ${ }^{1}$, Eleni Gavriilaki ${ }^{2}$, Nancy Hueppchen ${ }^{1}$, Karin Blakemore ${ }^{1}$, Xuan Yuan ${ }^{2}$, \\ Sara M. Seifert ${ }^{1}$, Sarah York ${ }^{3}$, and Robert A. Brodsky ${ }^{2}$ \\ ${ }^{1}$ Department of Gynecology and Obstetrics, Division of Maternal Fetal Medicine, Johns Hopkins \\ University School of Medicine \\ 2Department of Medicine, Division of Hematology, Johns Hopkins University School of Medicine \\ ${ }^{3}$ Department of Medicine, Division of Cardiology, Johns Hopkins University School of Medicine
}

\section{Abstract}

HELLP syndrome (hemolysis, elevated liver enzymes, and low platelets) is a severe variant of preeclampsia whose pathogenesis remains unclear. Recent evidence and clinical similarities suggest a link to atypical hemolytic uremic syndrome (aHUS), a disease of excessive activation of the alternative complement pathway effectively treated with a complement inhibitor, eculizumab. Therefore, we utilized a functional complement assay, the modified Ham test, to test sera of women with classic or atypical HELLP syndrome, preeclampsia with severe features, normal pregnancies and healthy non-pregnant women. Sera were also evaluated using levels of the terminal product of complement activation (C5b-9). We tested the in vitro ability of eculizumab to inhibit complement activation in HELLP serum. Increased complement activation was found in participants with classic or atypical HELLP compared to normal pregnancy and non-pregnant controls. Mixing HELLP serum with eculizumab containing serum resulted in a significant decrease in cell killing compared to HELLP serum alone. In conclusion, HELLP syndrome is associated with increased complement activation demonstrated by the modified Ham test. This assay may aid in the diagnosis of HELLP syndrome and confirm its pathophysiology relates to aHUS.

\section{Introduction}

Preeclampsia is a multisystem disorder of pregnancy which manifests as hypertension, proteinuria, and/or other end organ damage as a result of endothelial dysfunction, and occurs in $3-5 \%$ of all pregnancies [1]. Aside from its high prevalence, preeclampsia accounts for

Corresponding Author: Dr. Robert A. Brodsky, Ross Research Building, Room 1025, 720, Rutland Avenue, Baltimore, MD 21205-2196, Phone: 410-502-2546, Fax: 410-955-0185, rbrodsky@jhmi.edu.

Disclosure of Funding: E.G. was supported by the Johns Hopkins University School of Medicine Visiting Scientist LIBRA Initiative during the performance of this study. A.V. has received funding from the Johns Hopkins University School of Medicine Synergy Award for Innovative Research.

Publisher's Disclaimer: This is a PDF file of an unedited manuscript that has been accepted for publication. As a service to our customers we are providing this early version of the manuscript. The manuscript will undergo copyediting, typesetting, and review of the resulting proof before it is published in its final citable form. Please note that during the production process errors may be discovered which could affect the content, and all legal disclaimers that apply to the journal pertain. 
10-30\% of all preterm deliveries in developed countries [2, 3]. HELLP syndrome (hemolysis, elevated liver enzymes, and low platelets) is a severe variant of preeclampsia. Hematologist are often consulted because of thrombocytopenia and microangiopathy. First defined by Weinstein in 1982, HELLP syndrome has a reported incidence of up to $0.8 \%$ of all pregnancies [4]. For classic HELLP syndrome the Tennessee and Mississippi classifications propose clinical criteria using platelet count, lactate dehydrogenase (LDH) levels, bilirubin and aspartate aminotransferase (AST) with or without alanine aminotransferase (ALT) levels to establish the diagnosis (Table 1) [5, 6]. It is further acknowledged that many women with preeclampsia may have some but not all of these laboratory findings such as isolated thrombocytopenia or elevated liver enzymes without the classic disease. These women are categorized as "impending," "partial", "incomplete" or "atypical" HELLP and the criterion for this disease process varies [7, 8]

HELLP syndrome may result in severe morbidity and mortality to both the mother and fetus. Disseminated intravascular coagulopathy is the most frequent severe maternal complication followed by hepatic rupture and bleeding [7]. Delivery is the treatment of choice, but preterm delivery may have severe consequences to the neonate. Neonatal mortality and morbidity are significantly higher if the fetus is delivered before 34 weeks [9]. Treatment of HELLP prior to delivery is largely supportive and consists of fetal monitoring, steroids to increase fetal lung maturity, magnesium sulfate for maternal seizure prophylaxis, and pharmacologic management of hypertension [10-12].

Although the pathogenesis of HELLP is believed to be on the spectrum of preeclampsia via abnormal placentation, endothelial dysfunction, and release of vasoactive substances in the first trimester [13]), the cellular biology and natural history of disease that results in its distinct phenotype is not well defined. However, recent evidence implicates complement activation in its pathogenesis [14]. Studies have postulated an up-regulation of the alternative pathway of complement (APC) using markers in serum and urine (C5b-9 or membrane attack complex/MAC) [15, 16]. Recently, mutations in the APC have been found in up to $20 \%$ of HELLP patients [17]. Similar mutations are also found in atypical hemolytic uremic syndrome (aHUS), a disease of excess APC activation caused by inherited or acquired defects in the regulation of the APC [18]. Indeed, mothers with HELLP syndrome have manifestations very similar to aHUS which mainly involve microangiopathic hemolytic anemia (MAHA), thrombocytopenia, thrombotic microangiopathy, renal dysfunction, hypertension, seizures and altered mental status. Unlike HELLP, where the mainstay of therapy is limited to supportive care, expectant management and ultimately delivery, aHUS is treated with a C5 monoclonal antibody, eculizumab [19]. Eculizumab is approved by the Food and Drug Administration for the treatment of: a) paroxysmal nocturnal hemoglobinuria $(\mathrm{PNH})$, a complement-mediated hemolytic anemia due to deficiency of the complement regulatory proteins CD55 and CD59 from the red cell membrane[20, 21] and b) aHUS, a complement-driven thrombotic microangiopathy due to excessive complement activation in the serum [22]. Eculizumab is now considered the treatment of choice for both aHUS and PNH [23]. Eculizumab treatment has been also recently described in a case report of a HELLP patient with favorable effects [24]. 
We recently developed a sensitive and specific serum-based assay to detect heightened activity of the alternative pathway of complement ("modified Ham test") that readily distinguishes aHUS from other thrombotic microangiopathies such as thrombotic thrombocytopenic purpura [25] The principle of the modified Ham test is similar to the acidified serum (Ham) test that was developed by Dr. Thomas Ham in the 1930s to diagnose PNH [26, 27]. In PNH there is a genetic mutation, PIGA that causes deficiency or absence of glycosylphosphatidylinositol (GPI). Therefore, proteins anchored by GPI are missing. Two of those missing proteins are complement regulatory proteins (CD55 and CD59) on red cells [28]. Acidifying normal human serum activates the alternative pathway of complement and leads to specific lysis of PNH erythrocytes secondary to increased vulnerability to the activated complement in acidified serum, as shown in Figure 1A. In aHUS, there are usually genetic mutations or antibodies that lead to constitutive activation of the alternative pathway of complement in the patient's serum. Thus, when PNH-like reagent cells (GPI-deficient or $P I G A$-null TF-1 cells) are incubated with aHUS serum they rapidly accumulate C5b-9 and undergo cell death within hours [25]. Complement-induced death in the modified Ham test prevents conversion of a cell proliferation reagent (WST-1) into a red dye, formazan (Figure 1B). This colorimetric reaction allows one to detect complement-mediated killing in hours.

We hypothesized that a subset of women with atypical HELLP and classic HELLP syndrome may have increased APC activation similar to aHUS. To test this hypothesis, we used the modified Ham test to assess complement activation in patients with severe preeclampsia/HELLP syndrome.

\section{Methods and Materials}

\section{Study population}

We performed an observational, case-controlled study of women with classic HELLP (Group 1), atypical HELLP (Group 2), preeclampsia with severe features (Group 3), women with normal pregnancies (Group 4), and non-pregnant healthy women (Group 5). All participants, other than group 5, were greater than 23 weeks pregnant with no specified matching of gestational ages among groups. Preeclampsia with severe features was defined by the ACOG (American Congress of Obstetricians and Gynecologists) executive summary on hypertension in pregnancy [10]. Classic HELLP syndrome was defined as satisfying either Mississippi or Tennessee criteria. Atypical HELLP syndrome was defined as having at least one laboratory abnormality found in the Mississippi or Tennessee criteria for HELLP syndrome [5-7].

Groups 1, 2, and 3 were recruited antenatally from the Johns Hopkins Hospital and Johns Hopkins Bayview Medical Center from September 1, 2014 to August 31, 2015, and Group 4 and Group 5 were recruited from the institution's outpatient centers. Women with known sickle cell disease, systemic lupus erythematous, antiphospholipid antibody syndrome, or previously diagnosed microangiopathic and hemolytic diseases were excluded from all groups. Women with any hypertensive diseases of pregnancy were excluded from Group 4. All participants gave written informed consent, and the study was approved by the Johns Hopkins University Institutional Review Board. 
Blood from groups 1, 2, and 3 were collected at the time of admission and diagnosis, and blood from Group 4 and 5 was collected in the outpatient setting at the time of consent. The blood from all five groups was collected in serum separation tubes and was centrifuged at $4{ }^{\circ} \mathrm{C}$. Serum was separated and stored at $-80{ }^{\circ} \mathrm{C}$. Serum samples were processed and stored within 4 hours after the blood was drawn to prevent ex vivo complement activation. Coded samples were sent de-identified in the laboratory for further testing.

Given the expense of eculizumab treatment and its limited availability, the in vitro effects of eculizumab were tested utilizing serum from a patient treated with eculizumab for paroxysmal nocturnal hemoglobinuria (PNH), as previously described [29]. Eculizumab containing serum was drawn following informed consent from a treated patient within 60 minutes of eculizumab infusion, as a source of optimal eculizumab concentration

\section{Serum C5b-9 levels}

Serum C5b-9 levels were determined using a commercially available ELISA (enzyme-linked immunosorbent assay) kit (Quidel, San Diego, CA) according to the manufacturer's instructions.

\section{Modified Ham test}

The modified Ham test was performed as previously described ${ }^{16}$. Briefly, PNH-like reagent cells (PIGA-null TF-1 cell line) previously established in our laboratory were used as targets of complement-mediated killing. ${ }^{17}$. PIGA-null TF-1 cells were plated in U-shaped 96-well plates at a density of 4,000 cells / well and cultured until confluent. Then, cells were washed with PBS and incubated with $20 \%$ of serum in Gelatin Veronal Buffer (GVB, Sigma Aldrich, St Louis, MO) in triplicates for 30 minutes at $37^{\circ} \mathrm{C}$. Cells were washed again with PBS and incubated with the cell proliferation reagent 4-[3-(4-lodophenyl)-2-(4nitrophenyl)-2H-5-tetrazolio]-1.3-benzene disulfonate / WST-1 (Roche, Switzerland) for 2 hours at $37{ }^{\circ} \mathrm{C}$. The proliferation reagent was diluted in the cell culture medium at a concentration of 1:10 and $100 \mu \mathrm{l}$ of its solution was added per well. Absorbance was measured in an iMark Microplate Absorbance Reader (Bio-rad, Hercules, CA) at $490 \mathrm{~nm}$ with a reference wavelength at $595 \mathrm{~nm}$.

Heat-inactivated serum was used as a negative control. Heat inactivation was performed the same day of the experiment, incubating the serum at $56{ }^{\circ} \mathrm{C}$ for 30 minutes. Normal human AB serum (H4522, Sigma-Aldrich, St Louis, MO) was used as an internal control of the assay. Absorbance values of each sample were normalized after subtraction of the absorbance value of a blank well. Percentage of viable cells was expressed as a ratio of the absorbance of each sample multiplied by 100 , to the absorbance of the same sample's heatinactivated control. Thus, percentage of non-viable cells (cell killing) was calculated using the following formula: 100 - (sample absorbance * 100 / heat-inactivated sample's absorbance). Assay validation studies have indicated that sample storage at room temperature for more than 4 hours or overnight in a refrigerator results in higher than 50\% reduction of cell killing in the modified Ham test. Results are not affected by one cycle of sample freeze/thaw at $-80^{\circ} \mathrm{C}$ if all preparations are made on ice. 


\section{In vitro evaluation of complement inhibition}

Complement inhibition in vitro was evaluated using the modified Ham test. Eculizumab (ECU) containing serum from a PNH patient was mixed at different ratios with HELLP sera (50-50\%, 25-75\% and $12.5-87.5 \%$ of HELLP and ECU sera, respectively). Total amount of serum in the assay remained unchanged (20\%). Complement inhibition was also evaluated by adding $25 \mu \mathrm{g} / \mathrm{mL}$ of an anti-C5 monoclonal antibody solution (Alexion Pharmaceuticals). The total amount of serum in this assay remained unchanged at $20 \%$ as well.

\section{Statistical analysis}

Statistical analysis was performed using the Statistical Package for Social Sciences (SPSS) 20.0 for Windows (SPSS, Chicago, IL). The independent samples Student t-test was used to compare differences between the mean values of two groups. One-way ANOVA with Bonferroni's correction or nonparametric tests were used to compare means between more than two groups. Receiver operating characteristic (ROC) curve analysis was performed to determine the cut-off value, sensitivity and specificity of HELLP diagnosis by the modified Ham test. A p-value $₫ \mathbf{0} .05$ was considered statistically significant. Statistical power analysis was performed retrospectively calculating the observed power in a univariate analysis model.

\section{Results}

\section{Study population}

We studied sera from 14 women with classic HELLP syndrome (Group 1) and atypical (Group 2) HELLP syndrome, 7 women with preeclampsia with severe features (Group 3), 11 women with normal pregnancies (Group 4), and 8 controls (Group 5). Age was similar among participants with preeclampsia with severe features with or without HELLP (27.4 \pm 3.8 versus $26.3 \pm 5.4$ and $28.6 \pm 5.0$ for Groups 1,2 and $3, p=0.596)$. Laboratory and clinical characteristics of participants in Groups 1,2, and 3 are shown in Table 2. Two participants studied antepartum with preeclampsia with severe features but not HELLP, were also evaluated postpartum when they were diagnosed with classic HELLP and atypical HELLP.

\section{Serum C5b-9 levels}

We first studied C5b-9 (membrane attack complex) levels as a biomarker of terminal complement activation. C5b-9 is the terminal product of the complement cascade that lands on the cell membrane inducing complement-mediated cell killing. Although C5b-9 has been found increased in diseases with excess complement activation such as aHUS, the levels significantly overlap with diseases not characterized by systemic complement activation [30]. In the present study we, too, found no significant difference in serum C5b-9 levels among participants with preeclampsia with severe features with and without HELLP and normal controls ( $\mathrm{p}=0.808$ ), as shown in Figure 2.

\section{Modified Ham test}

We next sought to investigate complement activation in an assay that distinguished systemic complement activation observed in aHUS, the modified Ham test. The modified Ham test 
reflects complement activation as a percentage of complement-mediated cell killing and is thereby a functional assay. Greater than $21.5 \%$ killing of reagent cells was indicative of aHUS in our previous study of the modified Ham test ${ }^{16}$. As expected, healthy pregnant (Group 4) and non-pregnant (Group 5) controls presented similarly low cell killing $(4.9 \pm 7.0 \%$ versus $3.3 \pm 3.36 \%, \mathrm{p}=0.100)$. Participants in Groups 1 and 2 showed significantly higher percentage of cell killing than participants with normal pregnancy $(34.3 \pm 24.6 \%$ and $26.0 \pm 14.8 \%$ versus $4.9 \pm 7.0 \%, \mathrm{p}=0.001$ and $\mathrm{p}=0.002$ respectively). The observed power in the univariate analysis model was $86.7 \%$. Also, there was a trend towards significantly increased killing in Group 1 (classic HELLP) compared to Group 3 (preeclampsia with severe features) $(34.3 \pm 24.6 \%$ versus $13.0 \pm 11.7 \% \mathrm{p}=0.074)$. Interestingly, cell killing was above the cut-off value determined for aHUS diagnosis $(21.5 \%)$ in three out of four participants diagnosed with classic HELLP and seven out of ten participants diagnosed with atypical HELLP; cell killing due to complement was in the range seen for aHUS. One of the participants (case 3 in Table 2), had an increase in killing antenatally, and immediately after delivery was diagnosed with classic HELLP syndrome, suggesting she may have a genetic predisposition to HELLP as is often observed in aHUS. The other participant (case 5 in Table 2) had minimal cell killing antepartum but returned on postpartum day 4 with atypical HELLP syndrome and cell killing minimally above threshold value. Results are summarized in Figure 3A.

To determine a cut-off value above which the modified Ham test would be considered positive for HELLP diagnosis, we performed a ROC curve analysis that showed a significant area under the curve (area under the curve $=0.848$, $\mathrm{p}$-value $<0.001$ ). We were able to determine a percentage of non-viable cells higher than $20.5 \%$ as the cut-off value for the diagnosis of HELLP with $78.6 \%$ sensitivity and $92.9 \%$ specificity. ROC curve is shown in Figure 3B.

\section{In vitro evaluation of complement inhibition}

Eculizumab is highly effective in treating diseases of terminal complement activation such as PNH and aHUS. Therefore, we hypothesized that eculizumab would abrogate cell killing caused by HELLP serum in vitro. As expected, eculizumab-containing serum alone caused no increase in cell killing. However, mixing HELLP serum with increased cell killing with eculizumab-containing serum resulted in a significant decrease of cell killing compared to atypical HELLP sera alone suggesting that the cell killing induced from HELLP patient serum is complement-mediated and can be abrogated by terminal complement inhibition $(\mathrm{p}=0.007)$, Figure 4 . In order to show that eculizumab was directly responsible for inhibiting cell killing in the mixing studies, we added an anti-C5 monoclonal antibody (Alexion pharmaceuticals) directly to HELLP patient serum and performed the modified Ham test. As shown, in Figure 5, the anti-C5 monoclonal antibody markedly reduced cell killing at a dose of $25 \mu \mathrm{g} / \mathrm{mL}$.

\section{Discussion}

The present study provides evidence that there is increased complement activation through the alternative pathway of complement in a subset of women with preeclampsia with severe 
features and classic or atypical HELLP syndrome. This provides evidence of a link among preeclampsia, HELLP syndrome, and diseases of excess complement activation, namely aHUS. Furthermore, the modified Ham test appears to be a useful biomarker that may assist in the diagnosis of HELLP syndrome and if validated may help guide future clinical trials. HELLP syndrome is categorized as a severe form of preeclampsia. Limitations in the diagnosis of HELLP syndrome are the different criteria for classic HELLP syndrome and atypical HELLP syndrome, and a lack of reliable biomarkers. Moreover, severe preeclampsia, atypical and classical HELLP likely represent a clinical continuum and some patients are delivered before meeting clinical criteria for classical HELLP. In addition, LDH, AST and bilirubin are not specific for liver dysfunction and their elevation may be caused by intravascular hemolysis alone.

aHUS involves kidney injury and thrombotic microangiopathy similar to many cases of severe preeclampsia and HELLP. aHUS results from both inherited and acquired defects in the regulation of the alternative pathway of complement [18]. Mutations in genes regulating or activating the alternative pathway of complement involve serum (such as complement factor $\mathrm{H}$ and I, complement component C3) and cell membrane factors (such as CD46 or membrane cofactor protein and thrombomodulin). Genetic mutations in these complement regulatory genes are found in 50-60\% of patients diagnosed with aHUS [31, 32] and triggers (e.g, pregnancy, surgery, inflammation etc.) are considered crucial for the manifestation of the disease two-hit model[33]. Pregnancy is a common trigger for aHUS, accounting for 7$20 \%$ of cases, and $80 \%$ of pregnancy-associated aHUS is diagnosed in the postpartum period [34].

Genetic testing for aHUS is expensive, takes weeks to get the results and fails to diagnose almost $50 \%$ of cases; thus, there has been extensive research into finding more reliable biomarkers such as serum or urine levels of C5b-9, a marker of terminal complement activation. Although elevated in plasma of aHUS patients [30], C5b-9 levels cannot reliably distinguish aHUS from other thrombotic microagiopathies, such as thrombotic thrombocytopenic purpura (TTP) [25, 30]. Serum C5b-9 levels did not prove a reliable marker of complement activation in pregnant women with preeclampsia with severe features with or without HELLP. However, utilizing the modified Ham test we were able to show that classic and atypical HELLP sera cause increased complement-mediated cell killing to the same degree as aHUS serum. Indeed, the cut-off value defined for HELLP diagnosis was $20.5 \%$ whereas the cut-off value previously defined for aHUS was $21.5 \%$ [35]. Interestingly, one participant studied both antepartum and postpartum exhibited increased cell killing both times (case 3). The other participant who was studied both antepartum and postpartum showed no significant killing in the antepartum state, but was later diagnosed with atypical HELLP and showed significantly increased killing upon postpartum readmission, albeit marginally above threshold (case 4). If these findings are validated in larger cohorts, the modified Ham test may serve as a diagnostic test and help to identify patients who might benefit from complement inhibition treatment. Further studies are needed to determine whether or not the assay has predictive value for HELLP syndrome.

We have also shown that complement inhibition by eculizumab can effectively block activation of the alternative pathway of complement demonstrated as increased cell killing 
using the modified Ham test in HELLP serum. Through terminal complement inhibition by the monoclonal antibody, eculizumab has been established as a treatment of choice for aHUS. We decided to test whether complement inhibition is effective in HELLP serum utilizing this in vitro experiment. This experiment provides a mechanistic basis behind an already published case report of successful treatment with eculizumab ([24].

Demonstration of excess activation of the alternative pathway of complement in HELLP suggest that terminal complement inhibition may be effective in treating a subset of patients with HELLP. There is now increasing experience using eculizumab use in pregnant women with PNH [36-39] or pregnancy-related aHUS [40, 41]. No adverse maternal or fetal outcomes and no complications after breast feeding have been reported and eculizumab is not detected in fetal plasma [38, 42, 43]; the drug to not cross the placenta well and does not seem to get into breast milk.

Our study has limitations. First, the modified Ham test was negative in three out of fourteen participants with classic or atypical HELLP syndrome. Several possible explanations exist. The modified Ham test is serum-based and theoretically may not detect increased complement activation caused by mutations in cell membrane factors such as CD46 and thrombomodulin. Mutations in a membrane complement regulatory factor (CD46 or membrane cofactor protein) have been documented in case reports of patients with HELLP $[24,44]$ and in 4 out of 59 patients $(6.8 \%)$ with preeclampsia with severe features and/or HELLP syndrome studied [17]. Since mutations in other membrane complement regulatory factors in HELLP have not been studied yet, membrane abnormalities may account the negative results of the modified Ham test. Alternatively, other mechanisms and pathways beyond complement activation may also be involved in the spectrum of preeclampsia and HELLP syndrome. Another limitation is our relatively small sample size. Certainly, further studies are needed in a larger cohort of pregnant women.

In conclusion, we have shown that preeclampsia with severe features along with classic and atypical HELLP syndrome may be considered, at least in part, a disease of excessive complement activation. The modified Ham test may be a promising tool to identify patients with increased complement activation who might benefit from therapies that block complement activation. If confirmed in a larger cohort, the modified Ham test may be a valuable assay to select patients for such a clinical trial.

\section{Acknowledgments}

E.G. was a Johns Hopkins-Libra fellow during the performance of these studies. A.V. has received funding from the Johns Hopkins University School of Medicine Synergy Award for Innovative Research. Dr. Sammy Zakaria has supported this project as a Co- Investigator.

\section{References}

1. Pregnancy ACoOaGTFoHi. Hypertension in Pregnancy: Executive Summary \%U. Obstetrics \& Gynecology. 2013; 122:1122-1131. http://journals.lww.com/greenjournal/Fulltext/2013/11000/ Hypertension_in_Pregnancy_Executive_Summary.36.aspx. [PubMed: 24150027]

2. Chen XK, Wen SW, Smith GN, Yang Q, Walker MC. New-onset hypertension in late pregnancy and fetal growth: different associations between singletons and twins. Hypertension in pregnancy. 2007; 26:259-272. [PubMed: 17710575] 
3. Iacobelli S, Bonsante F, Robillard PY. Pre-eclampsia and preterm birth in Reunion Island: a 13 years cohort based study. Comparison With international data. The journal of maternal-fetal \& neonatal medicine : the official journal of the European Association of Perinatal Medicine, the Federation of Asia and Oceania Perinatal Societies, the International Society of Perinatal Obstet. 2015:1-22.

4. Weinstein L. Syndrome of hemolysis, elevated liver enzymes, and low platelet count: a severe consequence of hypertension in pregnancy. American journal of obstetrics and gynecology. 1982; 142:159-167. [PubMed: 7055180]

5. Sibai BM, Taslimi MM, el-Nazer A, Amon E, Mabie BC, Ryan GM. Maternal-perinatal outcome associated with the syndrome of hemolysis, elevated liver enzymes, and low platelets in severe preeclampsia-eclampsia. American journal of obstetrics and gynecology. 1986; 155:501-509. [PubMed: 3529964]

6. Martin JN Jr, Rinehart BK, May WL, Magann EF, Terrone DA, Blake PG. The spectrum of severe preeclampsia: comparative analysis by HELLP (hemolysis, elevated liver enzyme levels, and low platelet count) syndrome classification. American journal of obstetrics and gynecology. 1999; 180:1373-1384. [PubMed: 10368474]

7. Audibert F, Friedman SA, Frangieh AY, Sibai BM. Clinical utility of strict diagnostic criteria for the HELLP (hemolysis, elevated liver enzymes, and low platelets) syndrome. American journal of obstetrics and gynecology. 1996; 175:460-464. [PubMed: 8765269]

8. Sibai BM. Diagnosis, controversies, and management of the syndrome of hemolysis, elevated liver enzymes, and low platelet count. Obstetrics and gynecology. 2004; 103:981-991. [PubMed: 15121574]

9. Fanaroff AA, Stoll BJ, Wright LL, et al. Trends in neonatal morbidity and mortality for very low birthweight infants. American journal of obstetrics and gynecology. 2007; 196:147, e141-148. [PubMed: 17306659]

10. ACOG. Executive Summary: Hypertension in Pregnancy. American Obstetrics and Gynecology; 2013.

11. Fitzpatrick KE, Hinshaw K, Kurinczuk JJ, Knight M. Risk factors, management, and outcomes of hemolysis, elevated liver enzymes, and low platelets syndrome and elevated liver enzymes, low platelets syndrome. Obstetrics and gynecology. 2014; 123:618-627. [PubMed: 24499757]

12. Martin JN Jr, Rose CH, Briery CM. Understanding and managing HELLP syndrome: the integral role of aggressive glucocorticoids for mother and child. American journal of obstetrics and gynecology. 2006; 195:914-934. [PubMed: 16631593]

13. Uzan J, Carbonnel M, Piconne O, Asmar R, Ayoubi JM. Pre-eclampsia: pathophysiology, diagnosis, and management. Vascular health and risk management. 2011; 7:467-474. [PubMed: 21822394]

14. Fang CJ, Richards A, Liszewski MK, Kavanagh D, Atkinson JP. Advances in understanding of pathogenesis of aHUS and HELLP. British journal of haematology. 2008; 143:336-348. [PubMed: 18691170]

15. Haeger M, Unander M, Bengtsson A. Enhanced anaphylatoxin and terminal C5b-9 complement complex formation in patients with the syndrome of hemolysis, elevated liver enzymes, and low platelet count. Obstetrics and gynecology. 1990; 76:698-702. [PubMed: 2216207]

16. Burwick RM, Fichorova RN, Dawood HY, Yamamoto HS, Feinberg BB. Urinary excretion of C5b-9 in severe preeclampsia: tipping the balance of complement activation in pregnancy. Hypertension. 2013; 62:1040-1045. [PubMed: 24060886]

17. Salmon JE, Heuser C, Triebwasser M, et al. Mutations in complement regulatory proteins predispose to preeclampsia: a genetic analysis of the PROMISSE cohort. PLoS medicine. 2011; 8:e1001013. [PubMed: 21445332]

18. Cataland SR, Wu HM. Diagnosis and management of complement mediated thrombotic microangiopathies. Blood reviews. 2014; 28:67-74. [PubMed: 24534133]

19. Rother RP, Rollins SA, Mojcik CF, Brodsky RA, Bell L. Discovery and development of the complement inhibitor eculizumab for the treatment of paroxysmal nocturnal hemoglobinuria. Nature biotechnology. 2007; 25:1256-1264. 
20. Hillmen P, Young NS, Schubert J, et al. The complement inhibitor eculizumab in paroxysmal nocturnal hemoglobinuria. The New England journal of medicine. 2006; 355:1233-1243. [PubMed: 16990386]

21. Brodsky RA, Young NS, Antonioli E, et al. Multicenter phase 3 study of the complement inhibitor eculizumab for the treatment of patients with paroxysmal nocturnal hemoglobinuria. Blood. 2008; 111:1840-1847. [PubMed: 18055865]

22. Legendre CM, Licht C, Loirat C. Eculizumab in atypical hemolytic-uremic syndrome. The New England journal of medicine. 2013; 369:1379-1380. [PubMed: 24088105]

23. Legendre CM, Licht C, Muus $P$, et al. Terminal complement inhibitor eculizumab in atypical hemolytic-uremic syndrome. The New England journal of medicine. 2013; 368:2169-2181. [PubMed: 23738544]

24. Burwick RM, Feinberg BB. Eculizumab for the treatment of preeclampsia/HELLP syndrome. Placenta. 2013; 34:201-203. [PubMed: 23228435]

25. Gavriilaki E, Yuan X, Ye Z, et al. Modified Ham test for atypical hemolytic uremic syndrome. Blood. 2015; 125:3637-3646. [PubMed: 25862562]

26. Ham TH, Dingle JH. Studies on Destruction of Red Blood Cells. Ii. Chronic Hemolytic Anemia with Paroxysmal Nocturnal Hemoglobinuria: Certain Immunological Aspects of the Hemolytic Mechanism with Special Reference to Serum Complement. The Journal of clinical investigation. 1939; 18:657-672. [PubMed: 16694699]

27. Brodsky RA. Complement in hemolytic anemia. Blood. 2015; 126:2459-2465. [PubMed: 26582375]

28. Brodsky RA. Paroxysmal nocturnal hemoglobinuria. Blood. 2014; 124:2804-2811. [PubMed: 25237200]

29. Risitano AM, Notaro R, Pascariello C, et al. The complement receptor 2 /factor $\mathrm{H}$ fusion protein TT30 protects paroxysmal nocturnal hemoglobinuria erythrocytes from complement-mediated hemolysis and C3 fragment. Blood. 2012; 119:6307-6316. [PubMed: 22577173]

30. Cataland SR, Holers VM, Geyer S, Yang S, Wu HM. Biomarkers of terminal complement activation confirm the diagnosis of aHUS and differentiate aHUS from TTP. Blood. 2014; 123:3733-3738. [PubMed: 24695849]

31. Maga TK, Nishimura CJ, Weaver AE, Frees KL, Smith RJ. Mutations in alternative pathway complement proteins in American patients with atypical hemolytic uremic syndrome. Human mutation. 2010; 31:E1445-1460. [PubMed: 20513133]

32. Kavanagh D, Goodship T. Genetics and complement in atypical HUS. Pediatr Nephrol. 2010; 25:2431-2442. [PubMed: 20526633]

33. Noris M, Remuzzi G. Atypical hemolytic-uremic syndrome. The New England journal of medicine. 2009; 361:1676-1687. [PubMed: 19846853]

34. Fakhouri F, Roumenina L, Provot F, et al. Pregnancy-associated hemolytic uremic syndrome revisited in the era of complement gene mutations. Journal of the American Society of Nephrology : JASN. 2010; 21:859-867. [PubMed: 20203157]

35. Gavriilaki E, Yuan X, Ye Z, et al. Modified Ham test for atypical Hemolytic Uremic Syndrome. Blood. 2015

36. Kelly R, Arnold L, Richards S, et al. The management of pregnancy in paroxysmal nocturnal haemoglobinuria on long term eculizumab. British journal of haematology. 2010; 149:446-450. [PubMed: 20151973]

37. Patriquin C, Leber B. Increased eculizumab requirements during pregnancy in a patient with paroxysmal nocturnal hemoglobinuria: case report and review of the literature. Clinical case reports. 2015; 3:88-91. [PubMed: 25767703]

38. Hallstensen RF, Bergseth G, Foss S, et al. Eculizumab treatment during pregnancy does not affect the complement system activity of the newborn. Immunobiology. 2015; 220:452-459. [PubMed: 25468724]

39. Danilov AV, Brodsky RA, Craigo S, Smith H, Miller KB. Managing a pregnant patient with paroxysmal nocturnal hemoglobinuria in the era of eculizumab. Leukemia research. 2010; 34:566571. [PubMed: 19954846] 
40. Ardissino G, Wally Ossola M, Baffero GM, Rigotti A, Cugno M. Eculizumab for atypical hemolytic uremic syndrome in pregnancy. Obstetrics and gynecology. 2013; 122:487-489. [PubMed: 23884270]

41. Canigral C, Moscardo F, Castro C, et al. Eculizumab for the treatment of pregnancy-related atypical hemolytic uremic syndrome. Annals of hematology. 2014; 93:1421-1422. [PubMed: 24306089]

42. Sarris IGS, Koumis A, Elebute M, Shehata H, Penna L. Pregnancy outcome and safety of breastfeeding in two patients with paroxysmal nocturnal haemoglobinuria $(\mathrm{PNH})$ treated with eculizumab. Arch Dis Child Fetal Neonatal Ed. 2012; 97:A119.

43. Kelly RJHB, Kulasekararaj A, de Guibert S, Roth A, Weitz IC, Armstrong E, Hill A, Risitano AM, Patriquin CJ, Terriou L, Muus P, Turner MP, Schrezenmeier H, Szer J, Peffault de Latour R.

Eculizumab Treatment Improves Outcomes of Pregnancy in Patients with Paroxysmal Nocturnal Hemoglobinuria ASH abstract. 2014

44. Fang CJ, Fremeaux-Bacchi V, Liszewski MK, et al. Membrane cofactor protein mutations in atypical hemolytic uremic syndrome (aHUS), fatal Stx-HUS, C3 glomerulonephritis, and the HELLP syndrome. Blood. 2008; 111:624-632. [PubMed: 17914026] 


\section{Highlights}

- $\quad$ Serum from HELLP patients show activation of the alternative pathway of complement, similar to patients with atypical hemolytic uremic syndrome.

- $\quad$ Terminal complement blockade is effective in modulating excess complement in HELLP patients in vitro. 


\section{Math Formulae}

Percentage of non- viable cells $=100-($ sample absorbance $* 100 /$ heat- inactivated sampl sample's absorbance) 
Figure 1.

Model of the principle of the Ham and the modified Ham test. 
Figure 2.

Serum CSb-9 levels patients with preeclampsia with severe features with and without HELLP and normal - pregnant controls. No significant difference was found among the three groups $(\mathrm{p}=0.808)$. 
Figure 3. Modified Ham test in the HELLP syndrome

A. Participants with classic HELLP (cHELLP) and atypical HELLP (aHELLP) showed significantly higher percentage of cell killing than participants with normal pregnancy (34.3 $\pm 24.6 \%$ and $26.0 \pm 14.8 \%$ versus $4.9 \pm 7.0 \%, \mathrm{p}=0.001$ and $\mathrm{p}=0.002$ respectively) B. The ROC curve analysis showed a significant area under the curve (area under the curve $=0.848$, $\mathrm{p}$-value $<0.001$ ). We were able to determine a percentage of non-viable cells higher than $20.5 \%$ as the cut-off value for the diagnosis of HELLP with $78.6 \%$ sensitivity and $92.9 \%$ specificity. 
Figure 4.

Complement inhibition by anti-C5 monoclonal antibody (Eculizumab) abrogates cell killing in the modified Ham test 
Figure 5. Anti-C5 monoclonal antibody inhibits complement in HELLP serum

The modified Ham test was performed using $20 \%$ serum from a healthy control, a patient with atypical HUS (positive control), a patient with classic HELLP, and a patient with severe preeclampsia with increased killing in the modified Ham test. Each participant is represented as (*) with serum alone, and with $(\dagger)$ the addition of anti-C5 antibody $25 \mu \mathrm{g} / \mathrm{mL}$. The $y$-axis represents percent cell kill after 2 hours in the modified Ham test. Cell kill of greater than $20.5 \%$ is considered positive in this assay. The addition of anti-C5 antibody $(25 \mathrm{mg} / \mathrm{mL})$ to serum of all patient samples reduced cell kill in the modified Ham test to less than $20 \%$. 


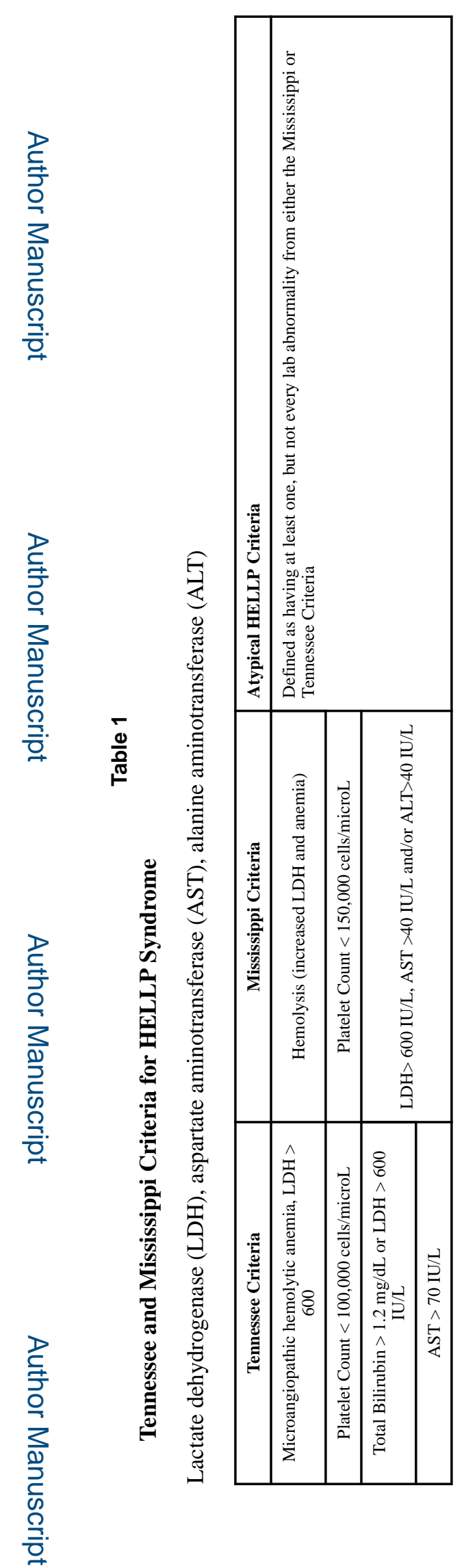

Exp Hematol. Author manuscript; available in PMC 2017 May 01. 


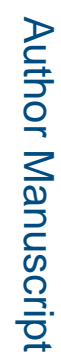

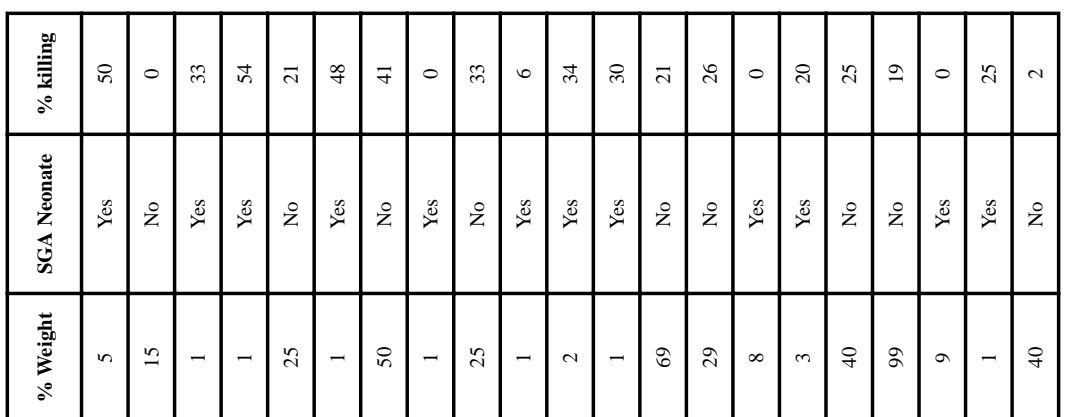

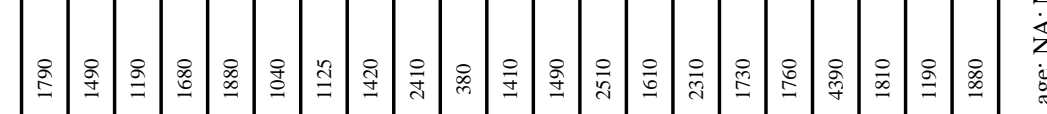

空

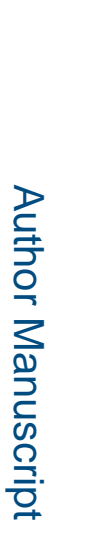

造
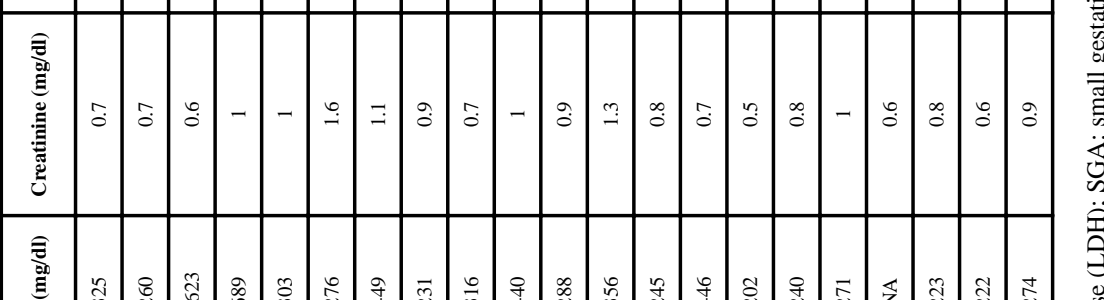

\section{諅}

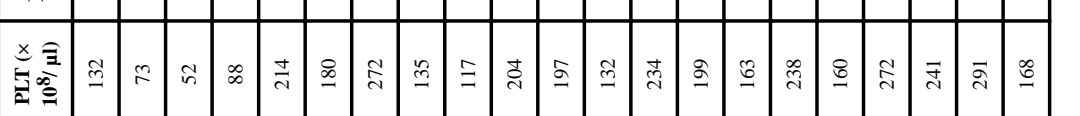

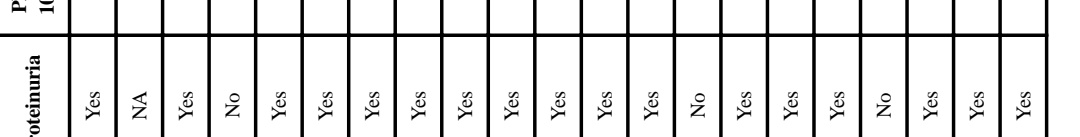

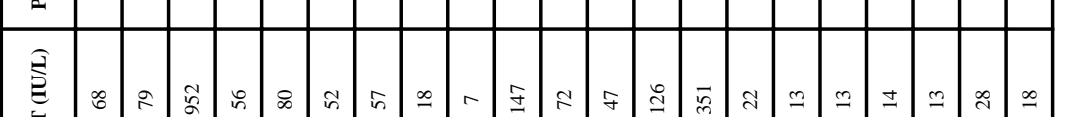

ᄅ

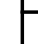

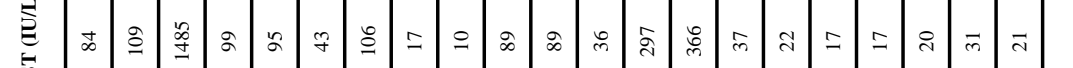

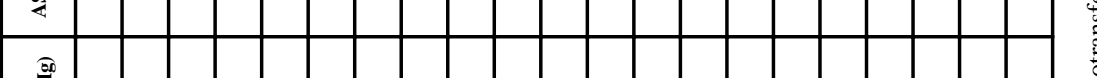

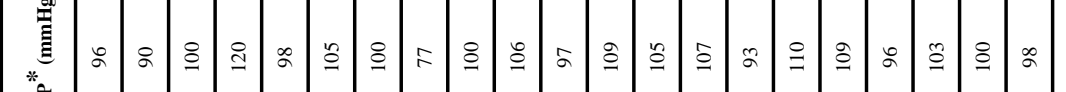

흘

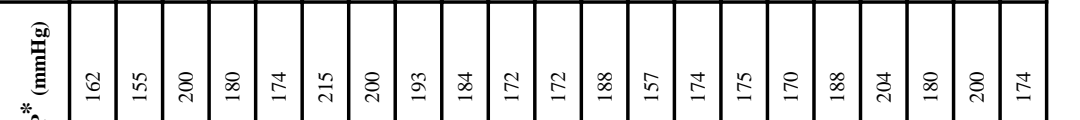

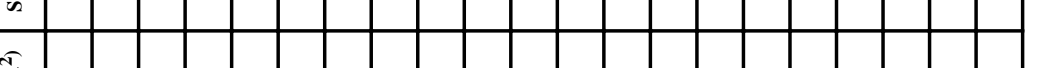

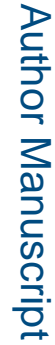

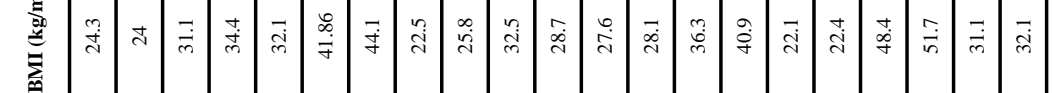

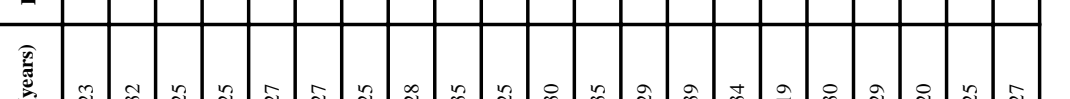

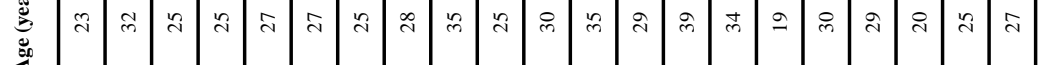

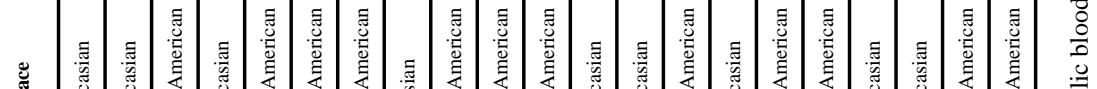

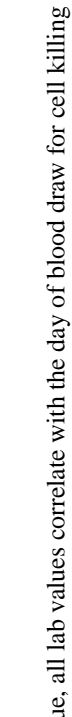

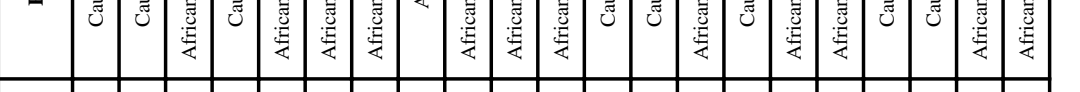

憘

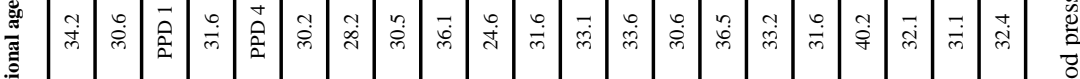

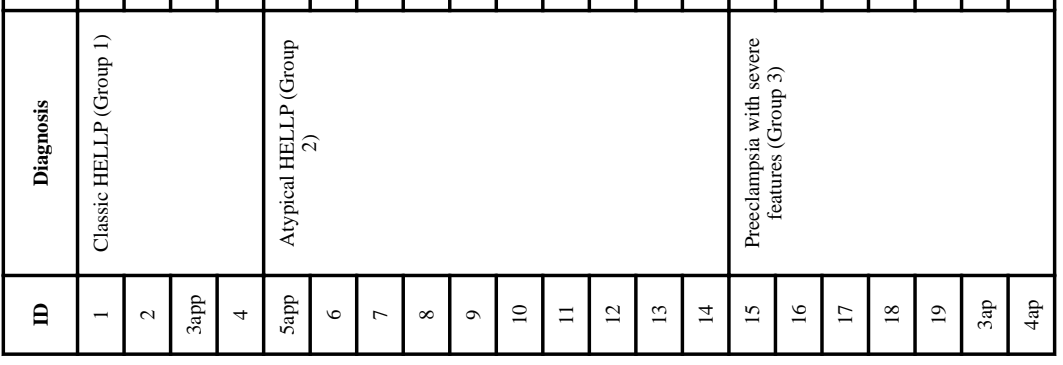

